\title{
Study on Hybrid Structure on TiO2 Nanorods and Graphene Enhanced P3HT for Solar Cells Application
}

\author{
Samir Mahdi AbdulAlmohsin \\ College of Science, Department of Physics, Thi Qar University, Thi Qar, IRAQ \\ Correspondence: samer.mahdi75@gmail.com
}

\begin{abstract}
Recently, hybrid structure graphene / organic nano composite have been studied for low cost photovoltaic devices (P3HT/Graphene ) can be formed by solution process at room temperature, in this study, we demonstrate a hybrid solar cells composite of (Graphene-P3HT/TiO2 Nanowire to allowed for distributed the organic materials among the nanorode, the organic which cover by spin coating to provide higher mobility and conductivity of (G-P3HT) where employed as P-type or Hole transparent materials with $\mathrm{TiO} 2 \mathrm{NW}$ as a photoanode. The nanocoposite of P3HT (G-P3HT, 10\% wt graphene) deposited on $\mathrm{TiO} 2 \mathrm{NW}$ by spin couter technique. The solar cells based on vertical $\mathrm{TiO} 2 \mathrm{NW}$ nanowire arrays by utilizing a spin couter spin speed. The initial results showed the power conversion efficiency of $0.5 \%$. The cells with G-P3HT showed different performance. The power conversion efficiency was improved from 0.3 for spin couter speed $300 \mathrm{rpm}$ to 1.3 at 500 rpm for G-P3HT among different spin speed solar cells. It exhibited tunable power conversion efficiency with spin speed, with very thin materials and in expensive processing, hybrid G/P3HT /Nanorod solar cells are promising as an economically viable alternative energy solution .
\end{abstract}

Keywords: Nanocomposite; graphene; organic electronics; metal oxide semiconductor; Hybrid structure solar cells

\section{Introduction}

Hybrid structure cells have attracted worldwide attention because of their low fabrication costs, promising light harvesting to energy conversion efficiency and environmental friendliness but it has modified recently by using nanocomposite material polymer -graphene (P3HTGraphene) because of the problems such as low in mobility of the organic materials low in efficiency and degradation of pure molecules therefore make nanocomposite improve the stability and increase the efficiency. Which may result increase charge separation and reduce charge recombination [1]. It has been demonstrated that heterojunction interface modification could improve the performance of hybrid device with appropriate modifiers, such as inorganic semiconductors and/or organic dye molecules [2-3]. Replacing the pristine of organic semiconductor with a nanocomposite represent solution to fix these issues. The high-energy conversion efficiency of hybrid solar cells are accomplished through the use of highly porous semiconductor as a nanorod films coated and penetrated among them [4].
Polymer such as poly(3-hexylthiophene), ( P3HT) is functioned as electron donor and generate excitons to transport holes within it to word the junction sets, while inorganic semiconductors such as $\mathrm{CdSe}, \mathrm{PbS}, \mathrm{TiO} 2$, and $\mathrm{ZnO}$ [5-8] serve as electron acceptor and electron transporter [9]. A promising photovoltaic device structure of organic-inorganic has been proposed [10]. The conjugated polymer infiltrated into the free spaces of the ordered nanostructure to form the active layer. However, an issue of chemical incompatibility between hydrophobic polymer and hydrophilic inorganic nanostructures exists in hybrid devices. They have the highest P-type activity with the different thickness. However, due to their high cost, alternative materials are intensively studied such as carbon black [11] carbon nanotube [12] and conjugated polymers [13]. Electronic polymers are promising candidates for Solar Cells as P-type semiconductor because of their unique properties, including low cost, good conductivity, remarkable stability and make very good Nanocomposite materials [14].

Many conductive polymers (poly pyrrole, polyaniline, poly (3,4-ethylenedioxythiophene), polythiophene) were 
investigated as materials for P-type materials. P3HT represent the most focus study polymers because of its very high absorption and good topographic smooth materials [7]. It is widely used in various applications such as super capacitors [8], field emission [9], sensors [10], dye-sensitized solar cells and Bulk hetrojunction solar cells. constructed P3HT films by dissolving $10 \mathrm{mg} / 1 \mathrm{ml}$ in chloroform and then affixed this polymer material to conductive glass, where it was used as hole transport materials[14]. This study obtained high power conversion efficiency $\sim 7.73 \%$. This high solar cell performance is most likely due to an increase in interfacial area of $\mathrm{TiO} 2$ nanorode.

Using P3HT film as hole transport materials on the top $\mathrm{TiO}_{2}$-dye conductive glass by spin coater deposition and used this as P-type electrodes of solar cells[13],[14].. They obtained promising results with the highest efficiency $\sim 0.3$ $\%$. Direct nanocomposite organic deposition on $\mathrm{TiO} 2 \mathrm{NW}$ make strong materials bonding to semi conductive surfaces. This will facilitate electron transport from the conductive glass then $\mathrm{TiO} 2 \mathrm{NW}$ to polymer so that improve solar cells performance where it so called Hybrid solar Cells.

In this present work, a combination of graphene -enriched P3HT (G-P3HT) as studied for hybrid NW solar cells Application. It was found that the use of nanocomposite materials of P3HT-G films has significant impact on the cell performance with different thickness due to different spin speed of spin coater. As a compare with pristine P3HT due to improved hole conduction in the polymer material .promising hybrid NW/polymer solar cells fabricated by using different spin speed of G-P3HT .The underline mechanisms are discussed in terms of improved electron collection through the optimum thickness. The performance of P3HT-graphene based on $\mathrm{TiO} 2$ nanorods as a photo anode where deposited at different spin speed. The influence upon solar cell performance was analyzed by I-V characteristic under light and dark. The polymer structure was characterized by scanning electron microscopy (SEM), $\mathrm{XRD}$, and CV spectroscopy

\section{Experimental Details}

The main purpose of this paper is to develop new novel nano-structured materials such as graphene, and composite nanostructure materials of conductive polymer P3HT with graphene. for low cost solar cell applications. The photovoltaic devices using organic-inorganic materials applied for hybrid solar cells.

\section{A- Materials synthesis}

P3HT mix 10\% wt graphene films :A ITO Indium Tin Oxide (ITO, sheet resistance $16 \Omega /$ sq) glass was used as the conducting substrate for the anode . P3HT use (Aldrich) $20 \mathrm{mg}$ and $10 \% \mathrm{wt}$ loading graphene dissolve them in $1 \mathrm{ml}$ chloroform then using a bath stirrer for $30 \mathrm{~min}$ to dispersing graphene with P3HT. Then, using spin coater $300,400,500,600,1000 \mathrm{rpm}$ to get very uniform thin films different thickness of $\mathrm{P} 3 \mathrm{HT} / \mathrm{G}$ as HTM and theTiO2 nanorods as photo anode .

TiO2 nanorods : TiO2 NWas were prepared on ITO glass by a hydrothermal process. Firstly, the clean $1.5 \times 2 \mathrm{~cm}^{2}$ ITO glass was immersed into a $0.2 \mathrm{M}$ of $\mathrm{TiCl} 4$ aqueous solution and then kept at $70{ }^{\circ} \mathrm{C}$ for 30 min, followed by heat tempering in air at $550{ }^{\circ} \mathrm{C}$ for 60 min. Afterwards, the ITO glass with $\mathrm{TiO} 2$ seed layer was located at an angle of $45^{\circ}$ against the wall of the Teflon-lined stainless steel autoclave $(100 \mathrm{~mL})$ with the conducting side facing down. $0.027 \mathrm{~mol} \mathrm{TiCl} 4$ was gradually dipped into the mixture solution with $30 \mathrm{~mL}$ of concentrated hydrochloric acid and $30 \mathrm{~mL}$ of ethyl alcohol. After stirring for $60 \mathrm{~min}$, the solution was transferred into the reaction kettle and heated at $150{ }^{\circ} \mathrm{C}$ for $720 \mathrm{~min}$. After self cooling to indoor temperature, the obtained samples were washed with DI water and ethyl alcohol for three times and natural dried.

Synthesis of graphene, P3HT, and P3HT-graphene Composites: The graphene were purchased from cheap tube as nanoplates, and the surface area equal $500 \mathrm{~cm}^{2} / \mathrm{g}$ semimetal. The P3HT-graphene nanocomposite was prepared with $10 \%$ wt graphene by the weight of polymer.

\section{B- Solar cell fabrication:}

Prepared ITO glass/TiO2 NW where dried naturally. Then, P3HT-graphene depositing by using spin couter technique onto the surfaces of FTO/TiO2 NW. The final devices were made by deposit the silver materials on the ITO glass/TiO2 NW /P3HT-G as a electrode as shown in Figure 7 as we seen that the active materials P3HT-G penetrate among $\mathrm{TiO} 2 \mathrm{NW}$ which contain of 
ITO glass/ TiO2 Thin Film /TiO2 NW/P3HT-G /Ag electrod. The light supplied on the ITO glass Side and finally absorb inside active material.

\section{C- Structural analyses:}

Figure 1 (a) and 1 (b) shows the SEM images of TiO2 nanorods, and cross section of $\mathrm{TiO} 2 \mathrm{NW}$ penetrate inside the nanocomposite materials. The top view and cross section of as-grown $\mathrm{TiO} 2$ nanorods shows the hexagonal structure of individual nanowires vertically aligned on the substrate. The average diameter of the nanorods is $200-300 \mathrm{~nm}$ with a density of 20 nanorods per $\mu \mathrm{m}^{2}$.

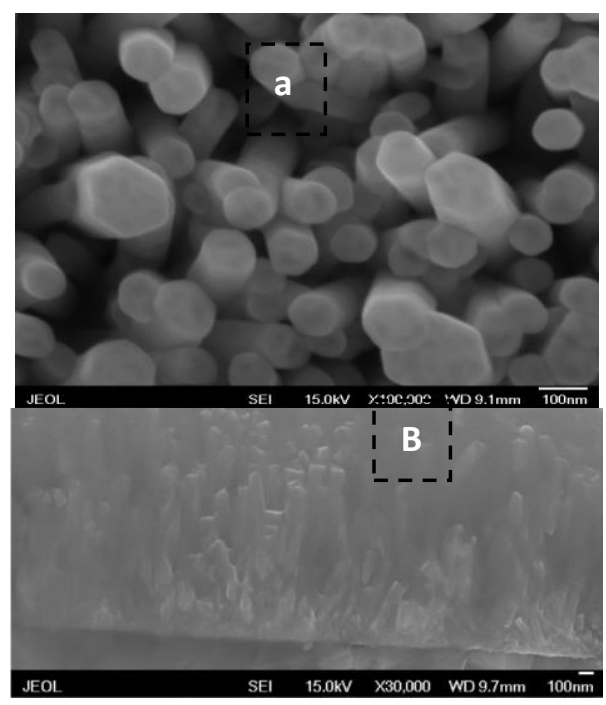

Fig 1(a): SEM images of TiO2 nanorods.

Figure 1(b): SEM images of $\mathrm{TiO} 2$ nanorods penetrate inside P3HT Thin Film

\section{Results and Discussion}

In this section, one it showed characterization of the nanocomposite materials of P3HT-graphene composites, as follows:

\section{1- Optical Properties of Materials}

The optical absorption spectrum of the poly $(3 \mathrm{HT})$ film was displayed from $300 \mathrm{~nm}$ to $800 \mathrm{~nm}$ in Figure 2. The most absorption range is from $430 \mathrm{~nm}$ to $620 \mathrm{~nm}$ which lies in the visible region. It should be distinguished that the strong global solar photons flux between $400 \mathrm{~nm}$ to $800 \mathrm{~nm}$ should be measured to be a main factor influence the photo induced carrier mechanism of a solar cell. The existence of $\mathrm{P} 3 \mathrm{HT}$ in the nanocomposite is characterized by the absorption band between 350 to $600 \mathrm{~nm}$, with a peak at 450 $\mathrm{nm}$. It can be seen that the P3HT-graphene nano composite /TiO2 NW has almost the same absorption range with little shift with peaks as that of the pure P3HT /TiO2 Nw structure in the wavelength range from 350 to $620 \mathrm{~nm}$, in addition to the absorption peak of the P3HT-graphene composite is broadened, and absorbs more strongly in the same. This should be caused by the absorption of graphene in the composite film. The absorption spectrum of the P3HT-G /TiO2 nanorod shows significant change upon adding $10 \%$ of graphene with a hetrostructure. This implies that in the P3HT-graphene composite, there is a significant ground-state interactions take place between the P3HTgrphene as HTM and TiO2 NW materials as a photo anode, and there is a charge transfer occurs between $\mathrm{TiO} 2 \mathrm{NW}$ and P3HT-G in the ground state, which is consistent with the literature [12].

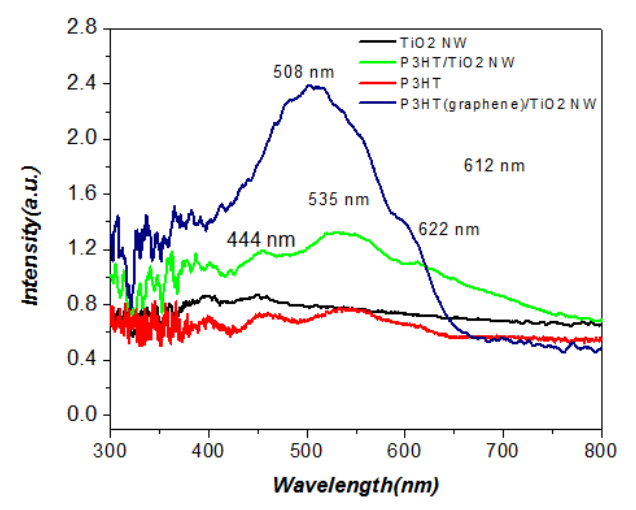

Fig 2: The Optical Absorption spectrum of $\mathrm{TiO} 2 \mathrm{NW}$, TiO2 NW/P3HT, and TiO2 NW /P3HT (graphene)

Figure 3 showed that the crystallographic structures of rough surface $\mathrm{TiO} 2$ NWAs were determined by the XRD, as shown in Figure 3The XRD pattern suggests that the all TiO2 NWAs can be ascribed to the Anatase phase. Moreover. A high intensity ( $\left.\begin{array}{lll}1 & 0 & 1\end{array}\right)$ diffraction peak at $25^{\circ}$ indicates that the Anatase $\mathrm{TiO} 2$ NWAs preferentially highly oriented grow along the c-axis. The similar diffraction peak location and full width at half-maximum of (101) diffraction peak suggests that the etching treatment does not disrupt the crystalline lattice of $\mathrm{TiO} 2$ NWAs. Further confirms the phase composition of the nanowire arrays can be ascribed to the Anates phase. 


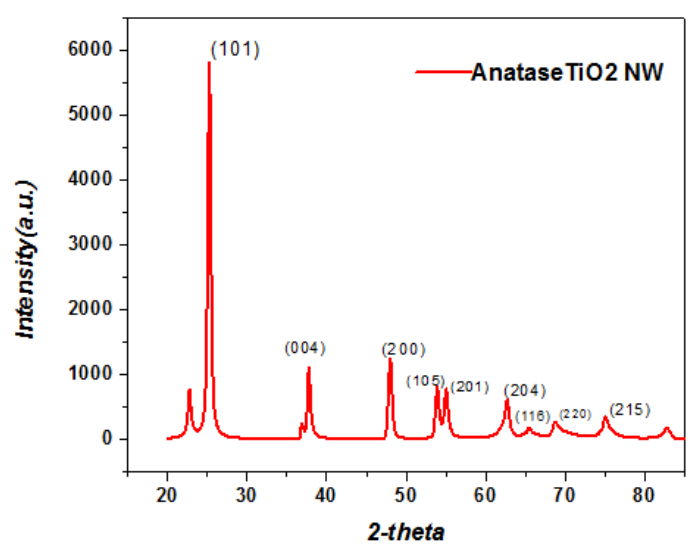

Fig 3: XRD spectrum of $\mathrm{TiO} 2 \mathrm{NW}$

Figure 4 show that EIS has been extensively employed to investigate the recombination of photogenerated electrons in the junction at the interface of $\mathrm{P}$ type and N-type, which is related to the charge transfer kinetics in solar cells [14]. Electrochemical impedance spectra (EIS) of the solar cells based on different thickness of P3HT-G due to different spin speed were also performed under light with $\mathrm{V}$ bias start from -2 to 2 volt. Nyquist plots mostly have two semicircles. The large semicircles with frequency region are attributed to the photogenerated electron recombination at the $\mathrm{P}-\mathrm{N}$ interface with $700 \mathrm{rpm}$, and the tiny semicircles region are attributed to $500 \mathrm{rpm}$ which represent the best result while others have different semicircles

Size to provide different internal resistivity and this result support the current -voltage characteristic at different spin speed

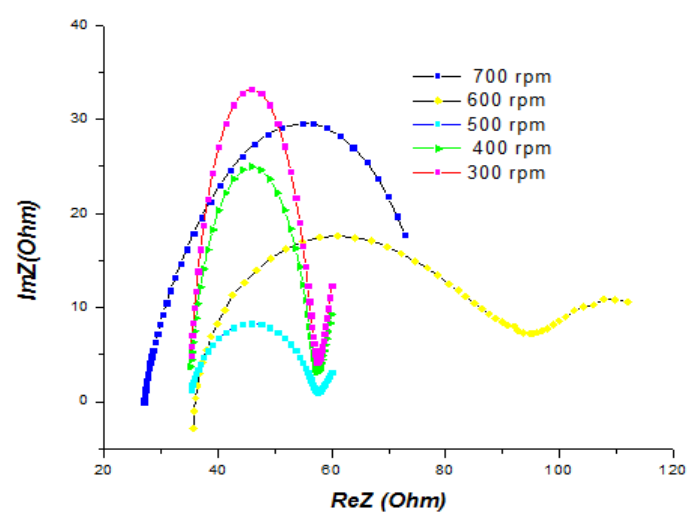

Fig 4: Electrochemical impedance spectroscopy of G$\mathrm{P} 3 \mathrm{HT} / \mathrm{ZnO} \mathrm{NW}$ solar cells prepare

\section{2- Current density-Voltage Characteristic}

Based on P3HT and P3HT mix 10\% wt graphene for $\mathrm{TiO} 2$ nanorod hetrostructure solar cells as in the figure 5 where the P3HT-G as HTM, as seen from the figures of I-V characteristic that best performance was with spin couter $500 \mathrm{rpm}$ among different spin speed of P3HT-G nanocomposite, due to graphene used to enrichment of P3HT and that will help decrease the internal resistivity. Furthermore, the performance of solar cells at $500 \mathrm{rpm}$ represent best PCE as we see from the Table 1, and Figure 5 the best efficiencies for the optimum condition which are $500 \mathrm{rpm}$ represent most efficient of hetrojunction solar cells.

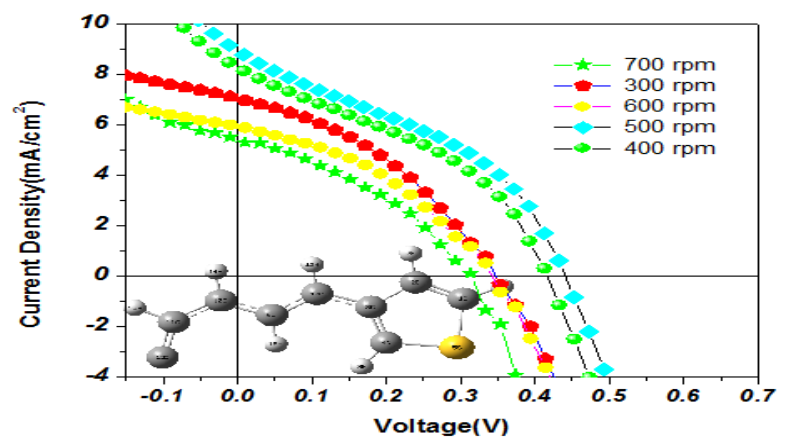

Fig 6: Current density vs. voltage measured on G$\mathrm{P} 3 \mathrm{HT} / \mathrm{ZnO}$ nanowire arrays different spin speed

Table 1: I-V values for hetrostructure solar cells.

\begin{tabular}{|l|l|l|l|c|}
\hline $\begin{array}{l}\text { solar Cell } \\
\text { parameter }\end{array}$ & $\mathbf{V}_{\text {oc }}$ & $\mathbf{I}_{\text {sc }}$ & FF & Efficiency \\
\hline Pristine P3HT & 0.35 & 1.57 & 0.36 & $0.311[11]$ \\
\hline $\begin{array}{l}\text { Nanocomposite } \\
\text { P3HT-G }\end{array}$ & 0.341 & 7 & 0.21 & 0.5 \\
\hline $\begin{array}{l}\text { P3HT-G for } 400 \\
\text { rpm rpm }\end{array}$ & 0.42 & 8.3 & 0.4 & 1.1 \\
\hline $\begin{array}{l}\text { P3HT-G for 500 } \\
\text { rpm }\end{array}$ & 0.44 & 9 & 0.328 & 1.3 \\
\hline
\end{tabular}




\section{Graphene Enhanced P3HT for Solar Cells Application}

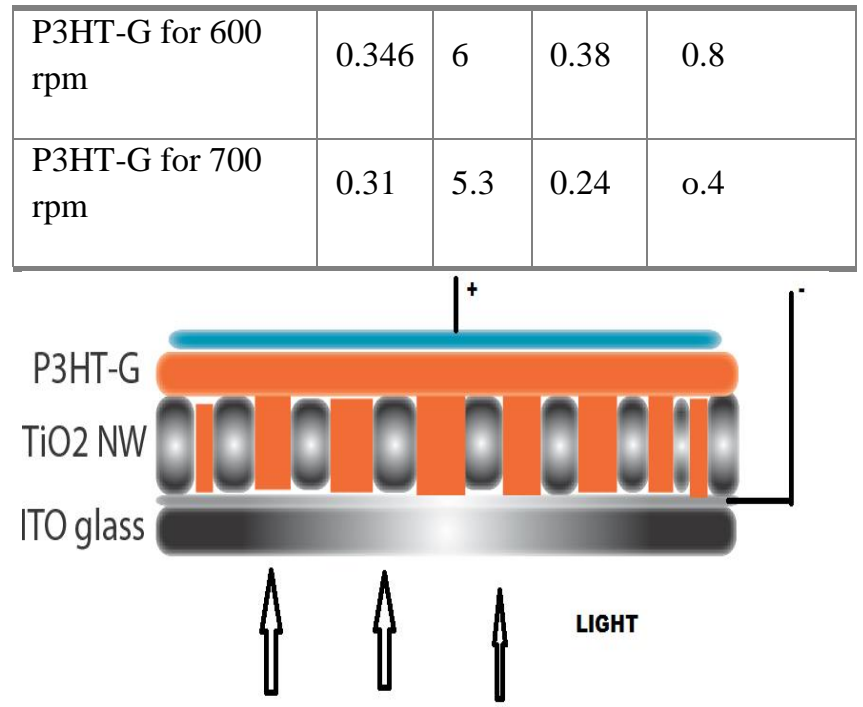

Fig 7: Schematic diagrams of the structure $\mathrm{TiO} 2 \mathrm{NW}$ /P3HT(graphene) Hetrostructure solar cells

\section{Conclusions}

Recently, graphene, a single layer hexagonal lattice of carbon atoms, has recently emerged with conductive polymer for improving properties of polymer because graphene possesses a range of unusual physical properties, therefore the efficiency increase when loading $10 \% \mathrm{wt}$ graphene with P3HT (HTM). Increasing in efficiency for the device TiO2 nanorod as anode solar cells with P3HT-G as a HTM with different thickness as impact of different spin speed. Spin couter at $500 \mathrm{rpm}$ where the efficiency reached to $1.3 \%$ among different spin speed and the solar cells less performance with $700 \mathrm{rpm}$ due to the thickness of HTM of G-P3HT make major tuneable due to the amount of light which absorb with life time of excitons.

\section{Acknowledgments}

We thank the Ministry of Higher Education and Scientific Research of Iraq for its support of scientific researches through the Iraqi Virtual Science Library (IVSL).

\section{References}

[1]- B. O'Regan and M. Gratzel, "A low-cost, highefficiency solar cell based on dye-sensitized colloidal TiO2 films," nature, vol. 353, pp. 737-740, 1991.

[2]- K. Keothongkham, S. Pimanpang, W. Maiaugree, S. Saekow, W. Jarernboon, and V. Amornkitbamrung,
"Electrochemically deposited polypyrrole for dyesensitized solar cell counter electrodes," International Journal of Photoenergy, vol. 2012, 2012.

[3]-T. N. Murakami, S. Ito, Q. Wang, M. K. Nazeeruddin, T. Bessho, I. Cesar, P. Liska, R. Humphry-Baker, P. Comte, and P. t. Pechy, "Highly efficient dye-sensitized solar cells based on carbon black counter electrodes," Journal of the Electrochemical Society, vol. 153, pp. A2255-A2261, 2006.

[4]-S. AbdulAlmohsin, M. Mohammed, Z. Li, M. A. Thomas, K. Y. Wu, and J. B. Cui, "Multi-walled carbon nanotubes as a new counter electrode for dye-sensitized solar cells," Journal of nanoscience and nanotechnology, vol. 12, pp. 2374-2379, 2012.

[5] S. M. M. a. M. S. AbdulAmohsin, M. Mohamed, "ZnO Nanowire/N719 Dye/Polythiophene-SWNT Nanocomposite Solid-state Dye Sensitized Solar Cells," Automation, Control and Intelligent Systems, vol. 3, pp. 12-17 2015.

[6]-Z. Li, B. Ye, X. Hu, X. Ma, X. Zhang, and Y. Deng, "Facile electropolymerized-PANI as counter electrode for low cost dye-sensitized solar cell," Electrochemistry Communications, vol. 11, pp. 1768-1771, 2009.

[7]-Y. Zhao, G. Yuan, P. Roche, and M. Leclerc, "A calorimetric study of the phase transitions in poly (3hexylthiophene)," Polymer, vol. 36, pp. 2211-2214, 1995. [8]-E. Frackowiak, V. Khomenko, K. Jurewicz, K. Lota, and F. Beguin, "Supercapacitors based on conducting polymers/nanotubes composites," Journal of Power Sources, vol. 153, pp. 413-418, 2006.

[9]-G. Lai, Z. Li, L. Cheng, and J. Peng, "Field Emission Characteristics of Conducting Polymer Films Conditioned by Electric Discharge," Journal of Materials Science and Technology, vol. 22, 2006.

[10]-H. Bai and G. Shi, "Gas sensors based on conducting polymers," Sensors, vol. 7, pp. 267-307, 2007.

[11]-S. Abdulalmohsin and J. B. Cui" Graphene-enriched $\mathrm{P} 3 \mathrm{HT}$ and porphyrin-modified $\mathrm{ZnO}$ nanowire arrays for hybrid solar cell applications". J. Phys. Chem. C 116, PP 9433-9438 (2012).

[12]-D. Yu, Y. Yang, M. Durstock, J.-B. Baek, and L. Dai, "Soluble P3HT-grafted graphene for efficient bilayerân" heterojunction photovoltaic devices," ACS nano, vol. 4, pp. 5633-5640, 2010.

[13]-Q. Liu, Z. Liu, X. Zhang, L. Yang, N. Zhang, G. Pan, S. Yin, Y. Chen, and J. Wei, "Polymer photovoltaic cells based on solution-processable graphene and P3HT," Advanced Functional Materials, vol. 19, pp. 894-904, 2009.

[14]F.Xie,J.Zhu,andY.Li,"TiO2-B as an electron transporting materials for highly efficient perovskite Solar Cells ,"Journal of power sources ,vol.415,pp.8-14,2019 